\title{
Common fixed points of two multivalued nonexpansive maps in Kohlenbach hyperbolic spaces
}

\section{Safeer Hussain Khan ${ }^{1 *}$ and Mujahid Abbas²}

"Correspondence:

safeerhussain5@yahoo.com; safeer@qu.edu.qa

${ }^{1}$ Department of Mathematics, Statistics \& Physic, Qatar University, Doha, 2713, Qatar

Full list of author information is available at the end of the article

\begin{abstract}
In this paper, we introduce an iteration scheme for two multivalued maps in Kohlenbach hyperbolic spaces. This extends the single-valued iteration process due to Agarwal et al. (J. Nonlinear Convex Anal. 8(1):61-79, 2007). Using this new algorithm, we approximate common fixed points of two multivalued mappings through $\triangle$-convergence and strong convergence under some weaker conditions. A necessary and sufficient condition is given for strong convergence.

MSC: Primary 47A06; 47H09; 47H10; secondary 49M05
\end{abstract}

Keywords: common fixed point; hyperbolic space; multivalued nonexpansive map; strong convergence; $\triangle$-convergence

\section{Introduction and preliminaries}

A subset $K$ of a metric space $X$ is proximinal if for each $x \in X$, there exists an element $k \in K$ such that

$$
d(x, K)=\inf \{d(x, y): y \in K\}=d(x, k) .
$$

Let $C B(K), C(K)$ and $P(K)$ be the families of closed and bounded subsets, compact subsets and proximinal bounded subsets of $K$, respectively. Let $H$ be the Hausdorff metric induced by the metric $d$ of $X$, that is,

$$
H(A, B)=\max \left\{\sup _{x \in A} d(x, B), \sup _{y \in B} d(y, A)\right\}
$$

for every $A, B \in C B(X)$. A multivalued map $T: K \rightarrow C B(X)$ is nonexpansive if

$$
H(T x, T y) \leq d(x, y)
$$

for all $x, y \in K$. A point $x \in K$ is a fixed point of $T$ if $x \in T x$. Denote the set of all fixed points of $T$ by $F(T)$ and $P_{T}(x)=\{y \in T x: d(x, y)=d(x, T x)\}$.

We consider the following definition of a hyperbolic space introduced by Kohlenbach [1].

(C) 2014 Khan and Abbas; licensee Springer. This is an Open Access article distributed under the terms of the Creative Commons Attribution License (http://creativecommons.org/licenses/by/2.0), which permits unrestricted use, distribution, and reproduction in any medium, provided the original work is properly cited. 
Definition 1 A metric space $(X, d)$ is a hyperbolic space if there exists a map $W: X^{2} \times$ $[0,1] \rightarrow X$ satisfying

(i) $d(u, W(x, y, \alpha)) \leq \alpha d(u, x)+(1-\alpha) d(u, y)$,

(ii) $d(W(x, y, \alpha), W(x, y, \beta))=|\alpha-\beta| d(x, y)$,

(iii) $W(x, y, \alpha)=W(y, x,(1-\alpha))$,

(iv) $d(W(x, z, \alpha), W(y, w, \alpha)) \leq \alpha d(x, y)+(1-\alpha) d(z, w)$

for all $x, y, z, w \in X$ and $\alpha, \beta \in[0,1]$.

In the sequel, we shall use the term hyperbolic space instead of Kohlenbach hyperbolic space for the sake of simplicity.

A metric space $(X, d)$ is called a convex metric space introduced by Takahashi [2] if it satisfies only (i). A subset $K$ of a hyperbolic space $X$ is convex if $W(x, y, \alpha) \in K$ for all $x, y \in K$ and $\alpha \in[0,1]$.

A hyperbolic space $(X, d, W)$ is uniformly convex [3] if for any $u, x, y \in X, r>0$, and $\epsilon \in(0,2]$, there exists a $\delta \in(0,1]$ such that $d\left(W\left(x, y, \frac{1}{2}\right), u\right) \leq(1-\delta) r$ whenever $d(x, u) \leq r$, $d(y, u) \leq r$ and $d(x, y) \geq \epsilon r$.

A map $\eta:(0, \infty) \times(0,2] \rightarrow(0,1]$ which provides such a $\delta=\eta(r, \epsilon)$ for given $r>0$ and $\epsilon \epsilon$ $(0,2]$, is known as the modulus of uniform convexity. We call $\eta$ monotone if it decreases with $r$ (for a fixed $\epsilon$ ).

Different definitions of hyperbolic space can be found in the literature (see for example [1, 4-6], for a comparison). The hyperbolic space introduced by Kohlenbach [1] is slightly restrictive than the space of hyperbolic type [4] but general than hyperbolic space of [7]. $C A T(0)$ spaces and Banach spaces are the examples of Kohlenbach hyperbolic spaces. Moreover, this class of hyperbolic spaces also contains Hadamard manifolds, Hilbert balls equipped with the hyperbolic metric [8], $\mathbb{R}$-trees and Cartesian products of Hilbert balls as special cases.

The study of fixed points for multivalued nonexpansive maps using Hausdorff metric was initiated by Markin [9] (see also [10]). The existence of fixed points for multivalued nonexpansive mappings in convex metric spaces has been shown by Shimizu and Takahashi [3]. Actually, they obtained the following.

Theorem ST ([3]) Let $(X, d)$ be a bounded, complete and uniformly convex metric space. Then every multivalued map $T: X \rightarrow C(X)$ (the family of all compact subsets of $X$ ) has a fixed point.

Later, an interesting and rich fixed point theory for such maps was developed which has applications in control theory, convex optimization, differential inclusion and economics (see [11] and references cited therein). Since then many authors have published papers on the existence and convergence of fixed points for multivalued nonexpansive maps in convex metric spaces.

The theory of multivalued nonexpansive maps is harder than the corresponding theory of single valued nonexpansive maps. Different iterative algorithms have been used to approximate the fixed points of multivalued nonexpansive maps. Sastry and Babu [12] considered Mann and Ishikawa type iterative algorithms.

The following is a useful lemma due to Nadler [10]. 
Lemma Let $A, B \in C B(E)$ and $a \in A$. If $\eta>0$, then there exists $b \in B$ such that $d(a, b) \leq$ $H(A, B)+\eta$.

Panyanak [13] proved some results using Ishikawa type iteration process without the condition $T p=\{p\}$ on the mapping $T$. Based on the above lemma, Song and Wang [14] modified the iterative algorithm due to Panyanak [13] and improved the results presented therein. Song and Wang [14] showed that without this condition his process was not well defined. They reconstructed the process using the condition $T p=\{p\}$ which made it well defined.

Recently, Shahzad and Zegeye [15] pointed out that the assumption $T p=\{p\}$ for any $p \in F(T)$ is quite strong. In order to get rid of the condition $T p=\{p\}$ for any $p \in F(T)$, they used $P_{T}(x):=\{y \in T x:\|x-y\|=d(x, T x)\}$ for a multivalued map $T: K \rightarrow P(K)$ and proved some strong convergence results using Mann and Ishikawa type iterative algorithms. Song and Cho [16] improved the results of [15] whereas Khan and Yildirim [17] used an iterative algorithm independent but faster than Ishikawa algorithm to further generalize the results of [16].

On the other hand Agarwal et al. [18] introduced the following iteration scheme for single valued mappings:

$$
\begin{aligned}
& x_{1} \in K, \\
& x_{n+1}=\left(1-\alpha_{n}\right) T x_{n}+\alpha_{n} T y_{n}, \\
& y_{n}=\left(1-\beta_{n}\right) x_{n}+\beta_{n} T x_{n}, \quad n \in \mathbb{N},
\end{aligned}
$$

where $0 \leq \alpha_{n}, \beta_{n} \leq 1$. This scheme is independent of both Mann and Ishikawa schemes. They proved that this scheme converges at a rate faster than Picard and Mann iteration schemes for contractions. Following their method, it was observed in Example 3.7 of Khan and Kim [19] that this scheme also converges faster than Ishikawa iteration scheme. Two mappings case of the above scheme has also been considered by many authors including [20-22].

In this paper, we first give a two-mappings version of the algorithm (1.1) in hyperbolic spaces and use $P_{T}(x)=\{y \in T x: d(x, y)=d(x, T x)\}$ instead of a stronger condition $T p=\{p\}$ for any $p \in F(T)$ to approximate common fixed points of two multivalued nonexpansive maps. We use the method of direct construction of Cauchy sequence as indicated by Song and Cho [16] (and opposed to [15]) but also used by many other authors including [17, 19, 23, 24]. Our algorithm in this paper is as follows:

Let $K$ be a nonempty convex subset of a hyperbolic space $X$. Let $S, T: K \rightarrow P(K)$ be two multivalued maps and $P_{T}(x)=\{y \in T x: d(x, y)=d(x, T x)\}$. Choose $x_{0} \in K$ and define $\left\{x_{n}\right\}$ as

$$
\left\{\begin{array}{l}
y_{n}=W\left(v_{n}, x_{n}, \frac{\beta_{n}}{1-\alpha_{n}}\right), \\
x_{n+1}=W\left(u_{n}, v_{n}, \alpha_{n}\right),
\end{array}\right.
$$

where $v_{n} \in P_{S}\left(x_{n}\right), u_{n} \in P_{T}\left(y_{n}\right)=P_{T}\left(W\left(v_{n}, x_{n}, \frac{\beta_{n}}{1-\alpha_{n}}\right)\right)$, and $\alpha_{n}, \beta_{n} \in(0,1)$ such that $\alpha_{n}+\beta_{n}<1$.

It follows from the definition of $P_{T}$ that $d(x, T x) \leq d\left(x, P_{T}(x)\right)$ for any $x$ in $K$. 
In order to verify that the algorithm (1.2) is well defined, define $f: K \rightarrow K$ by

$$
f(x)=W\left(u, v, \alpha_{1}\right)
$$

for some $v \in P_{S}(x)$, and for some $u \in P_{T}\left(W\left(v, x_{0}, \frac{\beta_{1}}{1-\alpha_{1}}\right)\right)$. Assume that $P_{S}$ and $P_{T}$ are nonexpansive multivalued mappings on $K$. For a given $x_{0} \in K$, the existence of $x_{1}$ is guaranteed if $f$ has a fixed point. Now, for any $m, n \in K$, let $y \in P_{S}(m), y^{\prime} \in P_{S}(n)$ such that $d\left(y, y^{\prime}\right)=d(y, S n)$, and $z \in P_{T}\left(W\left(y, x_{0}, \frac{\beta_{1}}{1-\alpha_{1}}\right)\right), z^{\prime} \in P_{T}\left(W\left(y^{\prime}, x_{0}, \frac{\beta_{1}}{1-\alpha_{1}}\right)\right)$ such that $d\left(z, z^{\prime}\right)=$ $d\left(z, T\left(W\left(y^{\prime}, x_{0}, \frac{\beta_{1}}{1-\alpha_{1}}\right)\right)\right)$.

On using (iv) of Definition 1, we have

$$
\begin{aligned}
& d(f(m), f(n)) \\
&= d\left(W\left(z, y, \alpha_{1}\right), W\left(z^{\prime}, y^{\prime}, \alpha_{1}\right)\right) \\
& \leq\left(1-\alpha_{1}\right) d\left(z, z^{\prime}\right)+\alpha_{1} d\left(y, y^{\prime}\right) \\
&=\left(1-\alpha_{1}\right) d\left(z, T\left(W\left(y^{\prime}, x_{0}, \frac{\beta_{1}}{1-\alpha_{1}}\right)\right)\right)+\alpha_{1} d(y, S n) \\
& \leq\left(1-\alpha_{1}\right) d\left(z, P_{T}\left(W\left(y^{\prime}, x_{0}, \frac{\beta_{1}}{1-\alpha_{1}}\right)\right)\right)+\alpha_{1} d\left(y, P_{S}(n)\right) \\
& \leq\left(1-\alpha_{1}\right) H\left(P_{T} W\left(y, x_{0}, \frac{\beta_{1}}{1-\alpha_{1}}\right), P_{T}\left(W\left(y^{\prime}, x_{0}, \frac{\beta_{1}}{1-\alpha_{1}}\right)\right)\right) \\
&+\alpha_{1} H\left(P_{S}(m), P_{S}(n)\right) \\
& \leq\left(1-\alpha_{1}\right) d\left(W\left(y, x_{0}, \frac{\beta_{1}}{1-\alpha_{1}}\right),\left(W\left(y^{\prime}, x_{0}, \frac{\beta_{1}}{1-\alpha_{1}}\right)\right)\right)+\alpha_{1} d(m, n) \\
& \leq\left(1-\alpha_{1}\right)\left(1-\frac{\beta_{1}}{1-\alpha_{1}}\right) d\left(y, y^{\prime}\right)+\alpha_{1} d(m, n) \\
&=\left(1-\alpha_{1}\right)\left(1-\frac{\beta_{1}}{1-\alpha_{1}}\right) d(y, S n)+\alpha_{1} d(m, n) \\
& \leq\left(1-\alpha_{1}\right)\left(1-\frac{\beta_{1}}{1-\alpha_{1}}\right) d\left(y, P_{S}(n)\right)+\alpha_{1} d(m, n) \\
& \leq\left(1-\alpha_{1}-\beta_{1}\right) H\left(P_{S}(m), P_{S}(n)\right)+\alpha_{1} d(m, n) \\
& \leq\left(1-\alpha_{1}-\beta_{1}\right) d(m, n)+\alpha_{1} d(m, n) \\
& \leq\left(1-\beta_{1}\right) d(m, n) .
\end{aligned}
$$

Since $\beta_{1} \in(0,1), f$ is a contraction. By the Banach contraction principle, $f$ has a unique fixed point. Thus the existence of $x_{1}$ is established. Continuing in this way, the existence of $x_{2}, x_{3}, \ldots$ is guaranteed. Hence the above algorithm is well defined.

In 1976, Lim [6] introduced the concept $\triangle$-convergence in metric spaces. In 2008, Kirk and Panyanak [25] specialized Lim's concept to $C A T(0)$ spaces and proved a number of results involving weak convergence in Banach spaces. Since then the notion of $\triangle$ convergence has been widely studied and a number of articles have appeared e.g., [8, 9, $11,12,26,27]$. To reach the definition of $\Delta$-convergence, we first recall the notions of asymptotic radius and asymptotic center as under: 
Let $\left\{x_{n}\right\}$ be a bounded sequence in a metric space $X$. For $x \in X$, define a continuous functional $r\left(x,\left\{x_{n}\right\}\right)$ by

$$
r\left(x,\left\{x_{n}\right\}\right)=\limsup _{n \rightarrow \infty} d\left(x, x_{n}\right) .
$$

Then

(i) $r_{K}\left(\left\{x_{n}\right\}\right)=\inf \left\{r\left(x,\left\{x_{n}\right\}\right): x \in X\right\}$ of $\left\{x_{n}\right\}$ is called the asymptotic radius of $\left\{x_{n}\right\}$ with respect to $K \subset X$;

(ii) for any $y \in K$,the set $A_{K}\left(\left\{x_{n}\right\}\right)=\left\{x \in X: r\left(x,\left\{x_{n}\right\}\right) \leq r\left(y,\left\{x_{n}\right\}\right)\right\}$ is called the asymptotic center of $\left\{x_{n}\right\}$ with respect to $K \subset X$.

If the asymptotic radius and the asymptotic center are taken with respect to $X$, then these are simply denoted by $r\left(\left\{x_{n}\right\}\right)$ and $A\left(\left\{x_{n}\right\}\right)$, respectively. In general, $A\left(\left\{x_{n}\right\}\right)$ may be empty or may even contain infinitely many points. It is well known that a complete uniformly convex hyperbolic space with monotone modulus of uniform convexity enjoys the property that bounded sequences have unique asymptotic center with respect to closed convex subsets [28].

A sequence $\left\{x_{n}\right\}$ in $X$ is said to $\triangle$-converge to $x \in X$ if $x$ is the unique asymptotic center of $\left\{x_{n_{i}}\right\}$ for every subsequence $\left\{x_{n_{i}}\right\}$ of $\left\{x_{n}\right\}$. In this case, we call $x$ the $\Delta$-limit of $\left\{x_{n}\right\}$ and write $\triangle-\lim _{n} x_{n}=x$.

The following are the key results to be used in our main results.

Lemma 1.1 ([29]) Let $K$ be a nonempty closed convex subset of a uniformly convex hyperbolic space and $\left\{x_{n}\right\}$ a bounded sequence in $K$ with $A\left(\left\{x_{n}\right\}\right)=\{y\}$. If $\left\{y_{m}\right\}$ is another sequence in $K$ such that $\lim _{m \rightarrow \infty} r\left(y_{m},\left\{x_{n}\right\}\right)=r\left(y,\left\{x_{n}\right\}\right)$, then $\lim _{m \rightarrow \infty} y_{m}=y$.

Lemma 1.2 ([29]) Let $(X, d, W)$ be a uniformly convex hyperbolic space with monotone modulus of uniform convexity. Suppose that $\left\{x_{n}\right\}$ and $\left\{y_{n}\right\}$ are sequences in $X$ and $x \in X$. Let $\left\{\alpha_{n}\right\}$ be a sequence with $0<b \leq \alpha_{n} \leq c<1$. If $\limsup _{n \rightarrow \infty} d\left(x_{n}, x\right) \leq r$, $\limsup \operatorname{su}_{n \rightarrow \infty} d\left(y_{n}, x\right) \leq r$ and $\lim _{n \rightarrow \infty} d\left(W\left(x_{n}, y_{n}, \alpha_{n}\right), x\right)=r$ for some $r \geq 0$, then $\lim _{n \rightarrow \infty} d\left(x_{n}, y_{n}\right)=0$.

\section{Main results}

The following lemma proved in [30] gives some properties of $P_{T}$ in metric (and hence hyperbolic) spaces.

Lemma 2.1 Let $K$ be a nonempty subset of a metric space $X$ and $T: K \rightarrow P(K)$ be a multivalued map. Then the following are equivalent:

(i) $x \in F(T)$, that is, $x \in T x$,

(ii) $P_{T}(x)=\{x\}$, that is, $x=y$ for each $y \in P_{T}(x)$,

(iii) $x \in F\left(P_{T}\right)$, that is, $x \in P_{T}(x)$.

Moreover, $F(T)=F\left(P_{T}\right)$.

In the sequel, $F=F(S) \cap F(T)$ denotes the set of all common fixed points of the multivalued maps $S$ and $T$.

Lemma 2.2 Let $K$ be a nonempty closed convex subset of a hyperbolic space $X$ and let $S, T: K \rightarrow P(K)$ be two multivalued maps such that $P_{T}$ and $P_{S}$ are nonexpansive maps and $F \neq \emptyset$. Then for the sequence $\left\{x_{n}\right\}$ in (1.2), $\lim _{n \rightarrow \infty} d\left(x_{n}, p\right)$ exists for each $p \in F$. 
Proof Let $p \in F$. Then $p \in P_{T}(p)=\{p\}$ and $p \in P_{S}(p)=\{p\}$. Using (1.2), we have

$$
\begin{aligned}
d\left(x_{n+1}, p\right) & =d\left(W\left(u_{n}, v_{n}, \alpha_{n}\right), p\right) \\
& \leq\left(1-\alpha_{n}\right) d\left(u_{n}, p\right)+\alpha_{n} d\left(v_{n}, p\right) \\
& \leq\left(1-\alpha_{n}\right) d\left(u_{n}, P_{T}(p)\right)+\alpha_{n} d\left(v_{n}, P_{S}(p)\right) \\
& \leq\left(1-\alpha_{n}\right) H\left(P_{T}\left(y_{n}\right), P_{T}(p)\right)+\alpha_{n} H\left(P_{S}\left(x_{n}\right), P_{S}(p)\right) \\
& \leq\left(1-\alpha_{n}\right) d\left(y_{n}, p\right)+\alpha_{n} d\left(x_{n}, p\right) \\
& \leq\left(1-\alpha_{n}\right) d\left(W\left(v_{n}, x_{n}, \frac{\beta_{n}}{1-\alpha_{n}}\right), p\right)+\alpha_{n} d\left(x_{n}, p\right) \\
& \leq\left(1-\alpha_{n}-\beta_{n}\right) d\left(v_{n}, p\right)+\beta_{n} d\left(x_{n}, p\right)+\alpha_{n} d\left(x_{n-1}, p\right) \\
& \leq\left(1-\alpha_{n}-\beta_{n}\right) H\left(P_{S}\left(x_{n}\right), P_{S}(p)\right)+\beta_{n} d\left(x_{n}, p\right)+\alpha_{n} d\left(x_{n}, p\right) \\
& \leq\left(1-\alpha_{n}-\beta_{n}\right) d\left(x_{n}, p\right)+\beta_{n} d\left(x_{n}, p\right)+\alpha_{n} d\left(x_{n}, p\right) \\
& \leq d\left(x_{n}, p\right) .
\end{aligned}
$$

That is,

$$
d\left(x_{n+1}, p\right) \leq d\left(x_{n}, p\right) .
$$

Hence $\lim _{n \rightarrow \infty} d\left(x_{n}, p\right)$ exists.

Lemma 2.3 Let $K$ be a nonempty closed convex subset of a uniformly convex hyperbolic space $X$ and let $S, T: K \rightarrow P(K)$ be two multivalued maps such that $P_{T}$ and $P_{S}$ are nonexpansive and $F \neq \emptyset$. Let $\left\{\alpha_{n}\right\}$ and $\left\{\beta_{n}\right\}$ satisfy $0<a \leq \alpha_{n}, \beta_{n} \leq b<1$. Then for the sequence $\left\{x_{n}\right\}$ in (1.2), we have $\lim _{n \rightarrow \infty} d\left(x_{n}, P_{S}\left(x_{n}\right)\right)=0=\lim _{n \rightarrow \infty} d\left(x_{n}, P_{T}\left(y_{n}\right)\right)$.

Proof By Lemma 2.2, $\lim _{n \rightarrow \infty} d\left(x_{n}, p\right)$ exists for each $p \in F$. Assume that $\lim _{n \rightarrow \infty} d\left(x_{n}, p\right)=$ $c$ for some $c \geq 0$. For $c=0$, the result is trivial. Suppose $c>0$.

Now $\lim _{n \rightarrow \infty} d\left(x_{n+1}, p\right)=c$ can be rewritten as

$$
\lim _{n \rightarrow \infty} d\left(W\left(u_{n}, v_{n}, \alpha_{n}\right), p\right)=c
$$

Since $P_{T}$ is nonexpansive, we have

$$
\begin{aligned}
d\left(u_{n}, p\right) & =d\left(u_{n}, P_{T}(p)\right) \\
& \leq H\left(P_{T}\left(y_{n}\right), P_{T}(p)\right) \\
& \leq d\left(y_{n}, p\right) \\
& =d\left(W\left(v_{n}, x_{n}, \frac{\beta_{n}}{1-\alpha_{n}}\right), p\right) \\
& \leq\left(1-\frac{\beta_{n}}{1-\alpha_{n}}\right) d\left(v_{n}, p\right)+\frac{\beta_{n}}{1-\alpha_{n}} d\left(x_{n}, p\right) \\
& \leq\left(1-\frac{\beta_{n}}{1-\alpha_{n}}\right) H\left(P_{S}\left(x_{n}\right), P_{S}(p)\right)+\frac{\beta_{n}}{1-\alpha_{n}} d\left(x_{n}, p\right)
\end{aligned}
$$




$$
\begin{aligned}
& \leq\left(1-\frac{\beta_{n}}{1-\alpha_{n}}\right) d\left(x_{n}, p\right)+\frac{\beta_{n}}{1-\alpha_{n}} d\left(x_{n}, p\right) \\
& =d\left(x_{n}, p\right) .
\end{aligned}
$$

Hence

$$
\limsup d\left(u_{n}, p\right) \leq c
$$

Next,

$$
\begin{aligned}
d\left(v_{n}, p\right) & =d\left(v_{n}, P_{S}(p)\right) \\
& \leq H\left(P_{S}\left(x_{n}\right), P_{S}(p)\right) \\
& \leq d\left(x_{n}, p\right)
\end{aligned}
$$

and so

$$
\limsup _{n \rightarrow \infty} d\left(v_{n}, p\right) \leq c
$$

Further,

$$
\begin{aligned}
d\left(W\left(x_{n}, v_{n}, \frac{\beta_{n}}{1-\alpha_{n}}\right), p\right) & \leq\left(1-\frac{\beta_{n}}{1-\alpha_{n}}\right) d\left(x_{n}, p\right)+\frac{\beta_{n}}{1-\alpha_{n}} d\left(v_{n}, p\right) \\
& \leq\left(1-\frac{\beta_{n}}{1-\alpha_{n}}\right) d\left(x_{n}, p\right)+\frac{\beta_{n}}{1-\alpha_{n}} d\left(x_{n}, p\right) \\
& =d\left(x_{n}, p\right) .
\end{aligned}
$$

Taking lim sup, we have

$$
\limsup _{n \rightarrow \infty} d\left(W\left(x_{n}, v_{n}, \frac{\beta_{n}}{1-\alpha_{n}}\right), p\right) \leq c
$$

Now (2.1) can be rewritten as

$$
\left(1-\alpha_{n}\right) d\left(x_{n+1}, p\right) \leq\left(1-\alpha_{n}\right) d\left(W\left(v_{n}, x_{n}, \frac{\beta_{n}}{1-\alpha_{n}}\right), p\right)+\alpha_{n} d\left(x_{n}, p\right)-\alpha_{n} d\left(x_{n+1}, p\right) .
$$

This implies that

$$
\begin{aligned}
d\left(x_{n+1}, p\right) & \leq d\left(W\left(v_{n}, x_{n}, \frac{\beta_{n}}{1-\alpha_{n}}\right), p\right)+\frac{\alpha_{n}}{1-\alpha_{n}}\left[d\left(x_{n}, p\right)-d\left(x_{n+1}, p\right)\right] \\
& \leq d\left(W\left(v_{n}, x_{n}, \frac{\beta_{n}}{1-\alpha_{n}}\right), p\right)+\frac{b}{1-b}\left[d\left(x_{n}, p\right)-d\left(x_{n+1}, p\right)\right]
\end{aligned}
$$

and, in turn,

$$
c \leq \liminf _{n \rightarrow \infty} d\left(W\left(x_{n}, v_{n}, \frac{\beta_{n}}{1-\alpha_{n}}\right), p\right) .
$$


Hence

$$
\lim _{n \rightarrow \infty} d\left(W\left(x_{n}, v_{n}, \frac{\beta_{n}}{1-\alpha_{n}}\right), p\right)=c .
$$

From $\lim _{n \rightarrow \infty} d\left(x_{n}, p\right)=c,(2.2),(2.3)$, and Lemma 1.2, it follows that

$$
\lim _{n \rightarrow \infty} d\left(x_{n}, v_{n}\right)=0
$$

Similarly we can show that

$$
\lim _{n \rightarrow \infty} d\left(x_{n}, u_{n}\right)=0
$$

Since $d\left(x, P_{S}(x)\right)=\inf _{z \in P_{S}(x)} d(x, z)$, therefore

$$
d\left(x_{n}, P_{S}\left(x_{n}\right)\right) \leq d\left(x_{n}, v_{n}\right) \rightarrow 0 \quad \text { as } n \rightarrow \infty .
$$

Similarly

$$
d\left(x_{n}, P_{T}\left(y_{n}\right)\right) \leq d\left(x_{n}, u_{n}\right) \rightarrow 0 \quad \text { as } n \rightarrow \infty
$$

We now prove $\triangle$-convergence of the algorithm (1.2).

Theorem 2.4 Let $K$ be a nonempty, closed, and convex subset of a uniformly convex hyperbolic space $X$ with monotone modulus of uniform convexity $\eta$ and $S, T, P_{T}, P_{S}$ and $\left\{x_{n}\right\}$ be as in Lemma 2.3. Then $\left\{x_{n}\right\} \triangle$-converges to a common fixed point of $S$ and $T$ (or $P_{S}$ and $\left.P_{T}\right)$.

Proof By Lemma 2.2, $\left\{x_{n}\right\}$ is bounded, therefore $\left\{x_{n}\right\}$ has a unique asymptotic center. Thus $A\left(\left\{x_{n}\right\}\right)=\{x\}$. Let $\left\{z_{n}\right\}$ be any subsequence of $\left\{x_{n}\right\}$ such that $A\left(\left\{z_{n}\right\}\right)=\{z\}$. Then $\lim _{n \rightarrow \infty} d\left(z_{n}, P_{T}\left(z_{n}\right)\right)=0=\lim _{n \rightarrow \infty} d\left(z_{n}, P_{S}\left(z_{n}\right)\right)$ by Lemma 2.3. We now prove that $u$ is a common fixed point of $P_{S}$ and $P_{T}$. For this, take $\left\{w_{m}\right\}$ in $P_{T}(u)$. Then

$$
\begin{aligned}
r\left(w_{m},\left\{z_{n}\right\}\right) & =\limsup _{n \rightarrow \infty} d\left(w_{m}, z_{n}\right) \\
& \leq \limsup _{n \rightarrow \infty}\left\{d\left(w_{m}, P_{T}\left(z_{n}\right)\right)+d\left(P_{T}\left(z_{n}\right), z_{n}\right)\right\} \\
& \leq \limsup _{n \rightarrow \infty} H\left(P_{T}(z), P_{T}\left(z_{n}\right)\right) \\
& \leq \limsup _{n \rightarrow \infty} d\left(z, z_{n}\right) \\
& =r\left(z,\left\{z_{n}\right\}\right) .
\end{aligned}
$$

This yields $\left|r\left(w_{m},\left\{z_{n}\right\}\right)-r\left(z,\left\{z_{n}\right\}\right)\right| \rightarrow 0$ as $m \rightarrow \infty$. Lemma 1.1 gives $\lim _{m \rightarrow \infty} w_{m}=z$. Note that $T z \in P(K)$ being proximinal is closed, hence $P_{T}(z)$ is closed. Moreover, $P_{T}(z)$ is bounded. Consequently $\lim _{m \rightarrow \infty} w_{m}=z \in P_{T}(z)$. Hence $z \in F\left(P_{T}\right)$. Similarly, $z \in F\left(P_{S}\right)$. Hence $z \in F$. Since $\lim _{n \rightarrow \infty} d\left(x_{n}, z\right)$ exists (by Lemma 2.2), therefore by the uniqueness of 
asymptotic center, we have

$$
\begin{array}{r}
\limsup _{n \rightarrow \infty} d\left(z_{n}, z\right)<\limsup _{n \rightarrow \infty} d\left(z_{n}, x\right) \\
\leq \limsup _{n \rightarrow \infty} d\left(x_{n}, x\right) \\
<\limsup _{n \rightarrow \infty} d\left(x_{n}, z\right) \\
=\limsup _{n \rightarrow \infty} d\left(z_{n}, z\right),
\end{array}
$$

a contradiction. Hence $x=z$. Thus $A\left(\left\{z_{n}\right\}\right)=\{z\}$ for every subsequence $\left\{z_{n}\right\}$ of $\left\{x_{n}\right\}$. This proves that $\left\{x_{n}\right\} \triangle$-converges to a common fixed point of $S$ and $T$ (or $P_{S}$ and $P_{T}$ ).

The following is a necessary and sufficient condition for the strong convergence of the algorithm (1.2).

Theorem 2.5 Let $K$ be a nonempty, closed, and convex subset of a complete hyperbolic space $X$ and $S, T, P_{T}, P_{S}$ and $\left\{x_{n}\right\}$ be as in Lemma 2.2. Then the sequence $\left\{x_{n}\right\}$ converges strongly to $p \in F$ if and only if $\liminf _{n \rightarrow \infty} d\left(x_{n}, F\right)=0$.

Proof If $\left\{x_{n}\right\}$ converges to $p \in F$, then $\lim _{n \rightarrow \infty} d\left(x_{n}, p\right)=0$. Since $0 \leq d\left(x_{n}, F\right) \leq d\left(x_{n}, p\right)$, we have $\liminf _{n \rightarrow \infty} d\left(x_{n}, F\right)=0$. To prove that the condition is also sufficient, assume that $\liminf _{n \rightarrow \infty} d\left(x_{n}, F\right)=0$. By Lemma 2.2, we have

$$
d\left(x_{n+1}, F\right) \leq d\left(x_{n}, F\right),
$$

and so $\lim _{n \rightarrow \infty} d\left(x_{n}, F\right)$ exists. By hypothesis $\liminf _{n \rightarrow \infty} d\left(x_{n}, F\right)=0$, thus $\lim _{n \rightarrow \infty} d\left(x_{n}\right.$, $F)=0$.

We now show that $\left\{x_{n}\right\}$ is a Cauchy sequence in $K$. Let $m, n \in N$ and assume $m>n$. Then it follows (along the lines similar to Lemma 2.2) that

$$
d\left(x_{m}, p\right) \leq d\left(x_{n}, p\right) \quad \text { for all } p \in F .
$$

Thus we have

$$
d\left(x_{m}, x_{n}\right) \leq d\left(x_{m}, p\right)+d\left(x_{n}, p\right) \leq 2 d\left(x_{n}, p\right) .
$$

Taking inf on the set $F$, we have $d\left(x_{m}, x_{n}\right) \leq d\left(x_{n}, F\right)$. On letting $m \rightarrow \infty, n \rightarrow \infty$, the inequality $d\left(x_{m}, x_{n}\right) \leq d\left(x_{n}, F\right)$ shows that $\left\{x_{n}\right\}$ is a Cauchy sequence in $K$ and hence converges, say to $q \in K$. Now it is left to show that $q \in F$. Indeed, by $d\left(x_{n}, F\left(P_{T}\right)\right)=$ $\inf _{y \in F\left(P_{T}\right)} d\left(x_{n}, y\right)$. So for each $\epsilon>0$, there exists $p_{n}^{(\epsilon)} \in F\left(P_{T}\right)$ such that

$$
d\left(x_{n}, p_{n}^{(\epsilon)}\right)<d\left(x_{n}, F\left(P_{T}\right)\right)+\frac{\epsilon}{3} .
$$

This implies $\lim _{n \rightarrow \infty} d\left(x_{n}, p_{n}^{(\epsilon)}\right) \leq \frac{\epsilon}{3}$. From $d\left(p_{n}^{(\epsilon)}, q\right) \leq d\left(x_{n}, p_{n}^{(\epsilon)}\right)+d\left(x_{n}, q\right)$, it follows that

$$
\limsup _{n \rightarrow \infty} d\left(p_{n}^{(\epsilon)}, q\right) \leq \frac{\epsilon}{3}
$$


Finally,

$$
\begin{aligned}
d\left(P_{T}(q), q\right) & \leq d\left(q, p_{n}^{(\epsilon)}\right)+d\left(p_{n}^{(\epsilon)}, P_{T}(q)\right) \\
& \leq d\left(q, p_{n}^{(\epsilon)}\right)+H\left(P_{T}\left(p_{n}^{(\epsilon)}\right), P_{T}(q)\right) \\
& \leq 2 d\left(p_{n}^{(\epsilon)}, q\right)
\end{aligned}
$$

yields $d\left(P_{T}(q), q\right)<\epsilon$. Since $\epsilon$ is arbitrary, therefore $d\left(P_{T}(q), q\right)=0$. Similarly, we can show that $d\left(P_{S}(q), q\right)=0$. Since $F$ is closed, $q \in F$ as required.

Recall that a map $T: K \rightarrow P(K)$ is semi-compact if any bounded sequence $\left\{x_{n}\right\}$ satisfying $d\left(x_{n}, T x_{n}\right) \rightarrow 0$ as $n \rightarrow \infty$ has a convergent subsequence.

We would also like to give here the definition of the so-called condition $\left(\mathrm{A}^{\prime}\right)$. Let $f$ be a nondecreasing selfmap on $[0, \infty)$ with $f(0)=0$ and $f(t)>0$ for all $t \in(0, \infty)$ and let $d(x, F)=\inf \{d(x, y): y \in F\}$. Let $S, T: K \rightarrow P(K)$ be two multivalued maps with $F \neq \emptyset$. Then the two maps are said to satisfy condition $\left(\mathrm{A}^{\prime}\right)$ if

$$
d(x, T x) \geq f(d(x, F)) \quad \text { or } \quad d(x, S x) \geq f(d(x, F)) \quad \text { for all } x \in K .
$$

Applying Lemma 2.3, we can easily obtain the following.

Theorem 2.6 Let $K$ be a nonempty closed convex subset of a complete and uniformly convex hyperbolic space $X$ with monotone modulus of uniform convexity $\eta$ and $S, T, P_{T}, P_{S}$ and $\left\{x_{n}\right\}$ be as in Lemma 2.3. Suppose that a pair of maps $P_{T}$ and $P_{S}$ satisfies condition $\left(\mathrm{A}^{\prime}\right)$, then the sequence $\left\{x_{n}\right\}$ defined in (1.2) converges strongly to $p \in F$.

Theorem 2.7 Let $K$ be a nonempty closed convex subset of a uniformly convex hyperbolic space $X$ with monotone modulus of uniform convexity $\eta$ and $S, T, P_{T}, P_{S}$ and $\left\{x_{n}\right\}$ be as in Lemma 2.3. Suppose that one of the map in $P_{T}$ and $P_{S}$ is semi-compact, then the sequence $\left\{x_{n}\right\}$ defined in (1.2) converges strongly to $p \in F$.

\section{Competing interests}

The authors declare that they have no competing interests.

\section{Authors' contributions}

Both authors worked on the manuscript. Both read and approved the final manuscript.

\section{Author details}

${ }^{1}$ Department of Mathematics, Statistics \& Physic, Qatar University, Doha, 2713, Qatar. ${ }^{2}$ Department of Mathematics and Applied Mathematics, University of Pretoria, Lynnwood road, Pretoria, 0002, South Africa.

\section{Acknowledgements}

The authors are greatly indebted to an anonymous referee for a very careful reading and pointing out necessary corrections.

Received: 18 March 2014 Accepted: 6 August 2014 Published: 2 September 2014

\section{References}

1. Kohlenbach, U: Some logical metatheorems with applications in functional analysis. Trans. Am. Math. Soc. 357, 89-128 (2005)

2. Takahashi, W: A convexity in metric spaces and nonexpansive mappings. Kodai Math. Semin. Rep. 22, 142-149 (1970)

3. Shimizu, T, Takahashi, W: Fixed points of multivalued mappings in certain convex metric spaces. Topol. Methods Nonlinear Anal. 8, 197-203 (1996)

4. Goebel, K, Kirk, WA: Iteration processes for nonexpansive maps. In: Singh, SP, Thomeier, S, Watson, B (eds.) Topological Methods in Nonlinear Functional Analysis (Toronto, 1982). Contemporary Mathematics, vol. 21, pp. 115-123 (1983) 
5. Kirk, WA: Krasnosel'skii iteration process in hyperbolic spaces. Numer. Funct. Anal. Optim. 4, 371-381 (1982)

6. Lim, TC: Remarks on some fixed point theorems. Proc. Am. Math. Soc. 60, 179-182 (1976)

7. Reich, S, Shafrir, I: Nonexpansive iterations in hyperbolic spaces. Nonlinear Anal., Theory Methods Appl. 15, 537-558 (1990)

8. Goebel, K, Reich, S: Uniform Convexity, Hyperbolic Geometry, and Nonexpansive Mappings. Dekker, New York (1984)

9. Markin, JT: Continuous dependence of fixed point sets. Proc. Am. Math. Soc. 38, 545-547 (1973)

10. Nadler, SB Jr: Multivalued contraction mappings. Pac. J. Math. 30, 475-488 (1969)

11. Gorniewicz, L: Topological Fixed Point Theory of Multivalued Maps. Kluwer Academic, Dordrecht (1999)

12. Sastry, KPR, Babu, GVR: Convergence of Ishikawa iterates for a multivalued mapping with a fixed point. Czechoslov. Math. J. 55, 817-826 (2005)

13. Panyanak, B: Mann and Ishikawa iterative processes for multivalued mappings in Banach spaces. Comput. Math. Appl. 54, 872-877 (2007)

14. Song, Y, Wang, H: Erratum to 'Mann and Ishikawa iterative processes for multivalued mappings in Banach spaces' [Comput. Math. Appl. 54 (2007) 872-877]. Comput. Math. Appl. 55, 2999-3002 (2008)

15. Shahzad, N, Zegeye, $\mathrm{H}$ : On Mann and Ishikawa iteration schemes for multi-valued maps in Banach spaces. Nonlinear Anal. 71, 838-844 (2009)

16. Song, Y, Cho, YJ: Some notes on Ishikawa iteration for multivalued mappings. Bull. Korean Math. Soc. 48, 575-584 (2011)

17. Khan, SH, Yildirim, I: Fixed points of multivalued nonexpansive mappings in Banach spaces. Fixed Point Theory Appl. 2012, Article ID 73 (2012). doi:10.1186/1682-1812-2012-73

18. Agarwal, RP, O'Regan, D, Sahu, DR: Iterative construction of fixed points of nearly asymptotically nonexpansive mappings. J. Nonlinear Convex Anal. 8(1), 61-79 (2007)

19. Khan, SH, Kim, JK: Common fixed points of two nonexpansive mappings by a modified faster iteration scheme. Bull. Korean Math. Soc. 47(5), 973-985 (2010)

20. Khan, $\mathrm{SH}$, Abbas, M: Approximating common fixed points of nearly asymptotically nonexpansive mappings. Anal. Theory Appl. 27(1), 76-91 (2011)

21. Khan, $\mathrm{SH}$, Cho, YJ, Abbas, M: Convergence to common fixed points by a modified iteration process. J. Appl. Math. Comput. 35, 607-616 (2011). doi:10.1007/s12190-010-0381-z

22. Turkmen, E, Khan, SH, Ozdemir, M: An iteration process for common fixed points of two nonself asymptotically nonexpansive mappings. Discrete Dyn. Nat. Soc. 2011, Article ID 487864 (2011). doi:10.1155/2011/487864

23. Khan, $\mathrm{SH}, \mathrm{Abbas}, \mathrm{M}$, Rhoades, BE: A new one-step iterative scheme for approximating common fixed points of two multivalued nonexpansive mappings. Rend. Circ. Mat. Palermo 59, 149-157 (2010)

24. Khan, SH, Fukhar-ud-din, H: Weak and strong convergence of a scheme with errors for two nonexpansive mappings. Nonlinear Anal. 8, 1295-1301 (2005)

25. Kirk, W, Panyanak, B: A concept of convergence in geodesic spaces. Nonlinear Anal. 68, 3689-3696 (2008)

26. Laokul, T, Panyanak, B: Approximating fixed points of nonexpansive maps in CAT(0) spaces. Int. J. Math. Anal. 3, 1305-1315 (2009)

27. Laowang, W, Panyanak, B: Strong and $\triangle$-convergence theorems for multivalued maps in CAT(0) spaces. J. Inequal. Appl. 2009, Article ID 730132 (2009)

28. Leustean, L: Nonexpansive iterations in uniformly convex W-hyperbolic spaces. http://arxiv.org/pdf/0810.4117.pdf. arXiv:0810.4117v1 [math.FA]

29. Fukhar-ud-din, H, Khan, AR, Khan, MAA: An implicit algorithm for two finite families of nonexpansive maps in hyperbolic spaces. Fixed Point Theory Appl. 2012, Article ID 54 (2012) http://www.fixedpointtheoryandapplications.com/content/2012/1/54

30. Fukhar-ud-din, H, Khan, SH, Kalsoom, A: Common fixed points of two multivalued nonexpansive maps by a one-step implicit algorithm in hyperbolic spaces. Mat. Vesn. 66, 4 (2014)

doi:10.1186/1687-1812-2014-181

Cite this article as: Khan and Abbas: Common fixed points of two multivalued nonexpansive maps in Kohlenbach

hyperbolic spaces. Fixed Point Theory and Applications 2014 2014:181.

\section{Submit your manuscript to a SpringerOpen ${ }^{\circ}$ journal and benefit from:}

- Convenient online submission

Rigorous peer review

- Immediate publication on acceptance

- Open access: articles freely available online

- High visibility within the field

- Retaining the copyright to your article 